\title{
Opportunities for Competitive Advantage in the Value Created by Primary Health Care Institutions in Lithuania: Is Competitiveness Dependent on the Form of Ownership?
}

Aida Budrevičiūtè ( $\square$ aida.budreviciute@gmail.com )

Lithuanian University of Health Sciences Medical Academy Public Health Faculty Department of Health Management

Ramunè Kalèdienè

Lithuanian University of Health Sciences Medical Academy Public Health Faculty Department of Health Management

Leonas Valius

Hospital of Lithuanian University of Health Sciences Kauno Klinikos

\section{Research Article}

Keywords: Health management, competitive advantage, primary health care, value creation, qualitative research, Lithuania

Posted Date: April 30th, 2021

DOI: https://doi.org/10.21203/rs.3.rs-439240/v1

License: (c) (i) This work is licensed under a Creative Commons Attribution 4.0 International License.

Read Full License 


\section{Abstract}

\section{Background.}

In the face of competition between primary health care institutions (PHCls), attempts are made to gain a competitive advantage in the market by creating greater value for patients. Applying and developing the professional skills of medical staff (family physicians and nurses) is important both in providing value to patients and in pursuit of the competitiveness of the institution. Little research has been conducted on whether the form of a PHCl's ownership is a factor of its competitive advantage.

The aim of the study.

To determine opportunities for competitive advantage in the management of value creation in public and private primary health care institutions by using the method of focus group discussion with managers.

\section{Methods.}

Focus group discussions were held in 10 Lithuanian counties, and 10 focus group sessions were carried out overall. A total of 48 primary health care managers were interviewed.

\section{Results.}

The competitive advantage of a $\mathrm{PHCl}$ depends on its form of ownership, which makes for unfair competitive conditions. A competitive advantage is created by factors such as: the variety of services available; the health care policy in action; the function of the manager; the professionalism of the staff; and the location of the institution. Medical staff have the same opportunities to express and develop their professional skills in public and private $\mathrm{PHCls}$, but private institutions attract the most skilled staff because they have the resources to increase their motivation.

\section{Conclusions.}

The managers of PHCls indicated that the competitive advantage depends on the form of ownership. In management science this study and the results can be a basis for the health care reform development and the foundation for new theories.

\section{Introduction}

Primary health care remains a priority in the development of the health care system. The importance of primary health care is defined by its role in providing services to the patient which are oriented towards meeting their needs and expectations and increasing their satisfaction. Growing competition between primary health care institutions allows patients to freely choose both their health care institution and their doctor. 
Service is the logic of value creation, and value creation for customers is the main objective of business and marketing (Grönroos, 2011). Value is analysed in the wider literature on services, and it is increasingly recognised that value creation is a process (Holmqvista et al., 2020). The value process is complex and involves the participation of companies, managers, staff, and consumers. In business, the value creation process is extensively analysed and the stages of the value creation process including value prediction, value understanding, value co-creation, value creation, and value learning are explored in great detail (Holmqvista et al., 2020). Value creation for patients is the main operating principle in optimally functioning health care systems (Porter, 2010). The value creation process in the health care sector, however, is rarely described, and therefore our focus group research is pertinent in bringing it to light.

In order to gain a competitive advantage, an organisation presents customers with a higher-value offer than their competitors (Ravald \& Grönroos, 1996). Organisations in the public service sector are at a disadvantage in this regard as, unlike privately-owned organisations, they possess no individual ownership nor responsibility, and they differ in their approach to the management of human resources, staff empowerment, and patient care (Bendell, Boulter \& Goodstadt, 1998).

Creating greater value for patients determines the competitive advantage of a $\mathrm{PHCl}$ and increases its competitiveness in the market. The influence that the form of a PHCl's ownership has on its competitive advantage has received little attention in scientific literature, therefore our study is both practically and scientifically significant. A qualitative study (focus group discussion) was performed to address the following questions:

- What are the factors of a PHCl's competitive advantage?

- Does the competitive advantage depend on the form of $\mathrm{PHCl}$ ownership?

- Which form of $\mathrm{PHCl}$ (public or private) provides the better opportunity for family physicians and nursing staff to express and develop their professional skills?

\section{Materials And Methods}

The focus groups were composed of a mean number of 5 participants, with a mean duration for their discussions of 1 hour 21 minutes. Contributors were chosen based on the Lithuanian Institute of Hygiene's 2012 index. Participants were selected on a 50 / 50 basis, aiming to include managers from private and public PHCls. Individuals were then approached by telephone and given information on the subject, aims, schedule, and location of the study. Once an agreement to participate had been received, an invitation was sent by e-mail and / or physically presented to the potential participant, or instead handed over to hospital staff who then passed it on to the prospective contributor. The sessions of study were audiotaped and then analysed from these records. In order to assess the quality of the focus group discussions, e-mail questionnaires were sent to the participants after the study. The focus group discussions involving the managers of PHCls were conducted from May 2015 to March 2016 in the 10 counties of Lithuania: Vilnius, Kaunas, Klaipèda, Šiauliai, Panevėžys, Utena, Alytus, Marijampolè, Tauragè, 
and Telšiai. A total of 48 participants were enrolled into the qualitative study: 31 managers of public $\mathrm{PHCls}$ and 17 managers of private PHCls.

The managers of both types of $\mathrm{PHCl}$ were presented with the following questions:

- Current management theories are customer-focused or, in the case of your health care institution, patient-focused. Is that factor alone enough for a health care institution to remain competitive?

- Which factors create a competitive advantage for a $\mathrm{PHCl}$ ?

- Do the competitive advantages of a $\mathrm{PHCl}$ depend on its form of ownership?

- If the competitive advantages of a $\mathrm{PHCl}$ depend on its form of ownership, what are these potential competitive advantages?

- Where can medical staff (family physicians and nursing staff) express and develop their professional skills better: in a public or a private $\mathrm{PHCl}$ ?

\section{Research Results}

\section{Current management theories are customer-focused or, in the case of your health care institution, patient- focused. Is that factor alone enough for a health care institution to remain competitive?}

The participants of the group discussions were asked if a patient-oriented approach is enough for a health care institution to remain competitive. Managers of public PHCls stated that competition ensures increased service quality and the exclusiveness of health care services compared to other forms of service. Managers of private PHCls also noted the economic aspect of the competitiveness of services, the necessity of competition in the health care sector, and the way in which competitiveness depends on health care policies. Managers of public PHCls indicated the following health care management areas that increase competitiveness: strengthening health care policy; encouraging competition between public and private $\mathrm{PHCls}$; the territorial distribution of $\mathrm{PHCls}$; and addressing individual health care issues in each municipality. Managers of private PHCls noted that the health care sector is heavily dependent on political decisions, meanwhile resources are used to create value for patients. Managers of public $\mathrm{PHCls}$ pointed out that changing public attitudes towards medicine, providing feedback to the public, promoting health activities, and strengthening public health functions should be the main public-focused activities. According to the participants of the group discussions, providing timely health care services to patients and ensuring the quality of these services is of the utmost importance. Managers of public PHCls also emphasised the importance of ensuring the quality of the services provided, alongside strengthening patient health through prevention and additional health care services in order to ensure the application of an integrated service. Participants of the group discussions acknowledged that medical services must be provided in accordance with established laws and regulations. Managers of private $\mathrm{PHCls}$ stated that an institution's activities must be patient-oriented and must pursue ethical and long-term competitiveness. Managers of public PHCls agreed that competition must rely on honesty, and that honesty is required so that patients have access to alternative options. The work of a family doctor should be concentrated on creating value for the patient, therefore the activities of a health care institution should be patient- 
focused. These activities should include: meeting the needs and expectations of patients; increasing patient satisfaction; increasing health literacy; improving communication with the patient; patient retention in accordance with legal regulations; strengthening contact with the patient; providing quality service to the patient; and encouraging the patient to take responsibility for their own health. According to the managers of private $\mathrm{PHCls}$, the value of a patient's health decreases if the patient is reluctant to make an effort to improve their health. Managers of public $\mathrm{PHCls}$ pointed out that patients frequently choose their health care provider based on location, and assess the family doctor's performance based on their communication skills rather than the quality of their service. Factors such as strengthening the self-worth of family doctors regarding their profession and increasing competition between specialists help an institution in its pursuit of competitiveness. Managers of private PHCls identified the main human resource activities that increase the competitiveness of a health care institution: strengthening primary level care; managing the workload of family doctors; motivating staff; building an internal culture; communicating sincerely with patients; communicating between nursing staff and patients; and pursuing the satisfaction of both family doctors and patients.

\section{Which factors create a competitive advantage for a $\mathrm{PHCl}$ ?}

Managers of public PHCls indicated that a competitive advantage is created through administrative factors (substitution, shared responsibility, and public procurement), diagnostic capabilities, infrastructure, resources, budget, the number of registered patients, and the location of the health care institution. Managers of private PHCls build their competitive advantage on their public image and prestige, their management of patient queues, the quality of their infrastructure, the convenience of their location, and the quality of their work. The participants of the group discussions noted the monotony of a family doctor's work, the prevalence of speed and automation, and the lack of creativity involved:

...A twenty-year relationship between a patient and their family doctor is a powerful motivator. The patient knows their doctor, the doctor knows their patient... (female respondent, public $\mathrm{PHCl}$, Panevėžys county)

The group discussion participants indicated that the human factor-communication-is essential in building the patient-doctor relationship. A patient chooses their doctor based on their communication skills more frequently than based on their work quality:

...Value creation-service quality and a patient's satisfaction with the service they received-is extremely important $<. . .>$ An amiable environment for the patient, sincere and professional communication, the convenience of the facilities, accessibility, parking options; it's all part of the service quality... (female respondent, private $\mathrm{PHCl}$, Klaipeda county)

The prevailing opinion is that a patient chooses their $\mathrm{PHCl}$ on a territorial basis, i.e. they choose the health care provider that is most conveniently located. Loyalty to one's family doctor is a common consideration, as many patients "migrate," i.e. they change their family doctor or their $\mathrm{PHCl}$. Managers of public $\mathrm{PHCls}$ noted that patients possess the power to address various regulatory institutions regarding the quality of medical care and the organisation of a PHCls work. Managers of private PHCls suggested service quality 
and culture, as well as building a close and personal relationship with the patient, as potential sources of competitive advantage. Managers of public $\mathrm{PHCls}$ singled out the management of human resources as an effective source of competitive advantage, which can derive from: hard-working administrative staff; a competent team (communication culture, emotional management); respectful attitudes towards staff; motivation; experience; qualifications; conference attendance and interest in innovations; competition between specialists; and the management of patient load and the duration of their visits. Managers of public $\mathrm{PHCls}$ also noted that family doctors should dedicate more time to medicine and treatment, reversing the recent trend of them becoming more akin to dispatchers who simply redistribute patients. Managers of private PHCls agreed that the value of a family doctor's work and their prestige in society should be increased. Managers of private PHCls also outlined elements of the management of human resources that play a role in creating a competitive advantage: teamwork (working towards a common goal; staff involvement); cooperation; employee satisfaction in their work; communication; and the attitudes of staff towards patients. According to Managers of public PHCls, competition should be honest, and more attention should be focused on building a legal base in accordance with the actual work performed by family doctors. Health care policy decisions could encompass such issues as managing staff burnout syndrome in medicine, the shortage of family doctors in rural areas, the territorial distribution of PHCls, the management of health care initiatives, and increasing competition among PHCls.

\section{Do the competitive advantages of a $\mathrm{PHCl}$ depend on its form of ownership?}

The majority of managers of both private and public PHCls indicated that competitive advantages depend on the form of ownership, which makes for unequal competitive conditions (Table 1).

According to the participants of the group discussions, one source of competitiveness stems from the fact that $\mathrm{PHCls}$ are dissimilar in their organisational structure. The group discussion study revealed the prevailing opinion that a larger organisation is more difficult to manage than a smaller one. Managers of public PHCls claimed that it is not the form of ownership but rather the attending doctor that creates the competitive advantage for the institution. The participants also indicated that private $\mathrm{PHCls}$ were the first choice among younger and higher-income patients. Managers of public $\mathrm{PHCls}$ stated that their private counterparts can create a more comfortable environment for patients. In addition, public $\mathrm{PHCls}$ face significant bureaucratic obstacles, whereas private PHCls find it easier to implement innovations and creative solutions, and are able to better meet the needs and expectations of their patients as a result. Public and private PHCls differ in the number of diagnostic tests performed on patients and the number

of consultations with secondary-level specialists. Managers of public PHCls support the idea of private insurance, and public and private PHCls distribute their earnings differently. According to managers of private $\mathrm{PHCls}$, cooperation between private and public institutions is important. Communication between family doctor and patient and a good atmosphere at work are a source of competitive advantage in private $\mathrm{PHCls}$. Managers of private $\mathrm{PHCls}$ emphasised that secondary prevention-i.e. educating patients about managing chronic diseases-is an important element that contributes to competitive advantage. Managers of public PHCls stated that smaller institutions have the advantage of their staff knowing their 
patients better, making it easier to provide preventative care and additional health care services. The participants of the group discussions expressed their opinion on health care policy, specifically on how the activities of municipal PHCls are determined by political decisions, and therefore the attitude of the state towards the activities of public and private $\mathrm{PHCls}$ is important. Managers of private $\mathrm{PHCls}$ stated that staff motivation and primary prevention services are sources of competitive advantage.

\section{If the competitive advantages of a $\mathrm{PHCl}$ depend on its form of ownership, what are these potential competitive advantages?}

Managers of public PHCls mentioned factors of competitive advantage that are contingent on the form of ownership: the organisational structure of the institution; staff workload; the principle of teamwork; location and facilities; and public image. The cumbersome organisational structures of public $\mathrm{PHCls}$ make it difficult to enact change. Better performance of public PHCls could be achieved by improving the work of reception staff and providing easier access to secondary-level specialists. Managers of private PHCls cited the following factors of competitive advantage: flexible and fast decision-making processes; and quicker and easier patient admissions, resulting in the quicker resolution of a patient's problem:

...Private [clinics] can compete through flexibility and speed: they can adapt, manage funds, hire and dismiss staff faster... (male respondent, public PHCl, Vilnius county)

Managers of private $\mathrm{PHCls}$ pointed out a competitive advantage of public $\mathrm{PHCls-assistance} \mathrm{from} \mathrm{the}$ founding body. Managers of public PHCls indicated that staff contribute to creating a competitive advantage, therefore decisions on qualifications, salaries, responsibility for a patient, and ensuring patient privacy are also key. Participants of the group discussions emphasised that a family doctor's popularity is not an indication of the quality of their work, which must be measured separately. Managers of private PHCls agree that staff form the competitive advantage, and so appropriate attention must be paid to staff motivation, creating contact between patient and family doctor, and the distribution of responsibilities between doctors and nursing staff. Managers of private $\mathrm{PHCls}$ stressed that the role of nursing staff in a $\mathrm{PHCl}$ must be clearly defined. Participants of the group discussion agreed on the necessity of defining patient home care within the primary health care chain. Managers of public $\mathrm{PHCls}$ stated that the name of the institution, as well as the doctor and their personality and communication skills, are important considerations for the patient. Participants of the group discussions indicated that many patients feel that a private health care institution generates greater value, and, consequently, a privately-employed doctor is associated with better value for the patient. Faced with competition for patients, the competitive advantage of a $\mathrm{PHCl}$ is formed through the effective management of patient queues and the duration of the visit. According to the managers of private $\mathrm{PHCls}$, personality is an important factor in family medicine, as the patient chooses the doctor. Managers of private PHCls also discussed how the competition between urban and rural institutions differs in terms of the value created for the patient, because the number of alternatives in rural areas is much lower. In the opinion of the participants of the group discussions, a competitive advantage is created through the variety of services provided. Managers of public $\mathrm{PHCls}$ indicated that municipal ownership does not constitute a 
competitive advantage, as all decisions must be coordinated with the founding body. Participants of the group discussions agreed that defining the concept of competition in the health care sector would be a worthwhile endeavour.

\section{Where can medical staff (family physicians and nursing staff) express and develop their professional skills better: in a public or a private $\mathrm{PHCl}$ ?}

Participants in the group discussions were asked in which $\mathrm{PHCl}$-private or public-medical staff (family doctors and nurses) can better apply and develop their professional skills. Managers of public $\mathrm{PHCls}$ indicated that medical staff have the same opportunities to do so in public and private settings, but managers of private $\mathrm{PHCls}$ can offer higher salaries to their staff, forcing public $\mathrm{PHCls}$ to compete to attract medical professionals. Public PHCls face staff management problems such as: nursing staff shortages; the management of burnout syndrome; staff protection; staff training; workload distribution; and staff motivation. Managers of private PHCls indicated such staff management issues as: nursing staff shortages; staff training; the management of intangible staff motivation; and the management of staff qualifications. Managers of private PHCls also noted that medical staff devote a large portion of their working time to paperwork, resulting in less time spent on providing medical care. According to managers of both sets of PHCls, it is important to evaluate the regulations that surround the work of family doctors so that more time can be devoted to actual medical work. The participants of the group discussions emphasised that the expression and development of the professional skills of medical staff depend on the preparation of both the manager and the employee, and therefore the focus is on increasing the professionalism of the employee as well. Unlike private $\mathrm{PHCls}$, public $\mathrm{PHCls}$ engage in organising work, creating a family atmosphere, preparing internal rules, organising public procurement, and performing the management of losses. However, staff management in public $\mathrm{PHCls}$ is constrained by the legal framework and the health care policy, which includes provisions on the speed of decisionmaking and the nature of cooperation between health care institutions. Managers of private $\mathrm{PHCls}$ indicated that medical staff in private institutions can better express and develop their professional skills, because the competencies of each employee come into play:

...Attracting patients and finding and attracting employees are priorities. Private primary health care institutions strive to attract and retain the best employees. $<. . .>$ Patients are more frequently dissatisfied with the receptionist's work than that of the doctor... (male respondent, public $\mathrm{PHCl}$, Kaunas county)

The group discussions revealed the opinion that private $\mathrm{PHCls}$ attract the top medical professionals. The disclosure of the qualifications of an institution's medical staff increases its attractiveness to patients, and therefore the managers of private $\mathrm{PHCls}$ devote a lot of attention to the creation of added value within the institution, which often involves the development of internal culture, event management, and staff training. Managers of both private and public PHCls indicated that competitive advantage is created by the effective management of patient queues, duration of visit, and the quality of the services provided by the family physician. The majority of managers of both private and public PHCls stated that the competitive advantage of a primary health care institution depends on the form of ownership of the 
institution, and that competitive advantage is created by: the health care policy in action; the function of the manager; the professionalism of the staff; and the location of the institution.

\section{Discussion}

Competition is encouraged in the business sector, as it leads to consumer satisfaction and greater value creation for the customer (Rivers \& Glover, 2008). Competition in the health care sector is perceived through the following lenses: competition and health care quality; competition and health care expense; and competition and patient satisfaction (Rivers \& Glover, 2008). Our qualitative study revealed that competition between $\mathrm{PHCls}$ is necessary, as it ensures the quality of health care services. The participants of the group discussions conducted as part of this research emphasised the economic competitiveness of services and the degree to which the country's health care policy enables competitive conditions.

Researchers of the resource-based management theory have previously stated that long-term competitive advantage is created by an institution's own resources (Wernerfelt, 1984; Oliver, 1997). The scientific literature outlines factors of competitive advantage associated with the business environment, the needs of consumers, the actions of competitors, and the internal resources of an institution (Prajogo \& McDermott, 2011). Little has been investigated regarding the factors that create a competitive advantage in the health care sector. Our study of group discussions revealed the factors that create a competitive advantage for $\mathrm{PHCls}$ according to the form of their ownership. Private $\mathrm{PHCls}$ create a competitive advantage by: improving the institution's public image and prestige; introducing patient queue management; upgrading infrastructure; being situated in a convenient location; and improving work quality. Public PHCls create a competitive advantage by: performing administrative activities; offering patient health prevention measures and disease diagnostics; upgrading infrastructure; managing budgets; treating an increased number of patients; and being situated in a convenient location.

The form of ownership of the $\mathrm{PHCl}$ is one of the factors that enables the efficient operation of an institution (Herrera et al., 2014). Admittedly, for-profit private $\mathrm{PHCls}$ provide more efficient health care services because a portion of their profits is allocated to improving performance (Herrera et al., 2014). However, making a profit is not the main objective in the field of health care; patient well-being, prestige, research, training, and developing technologies are the primary goals of health care institutions (Herrera et al., 2014). Our qualitative study found that the competitive advantage of an institution depends on its form of ownership (public or private). Managers of public PHCls noted the following features of their competitive advantage: the organisational structure of their institution; the workload of staff; the principle of teamwork; their location and facilities; and their public image. Managers of private PHCls cited the following features of their competitive advantage: flexible and fast decision-making processes; and the quicker and easier admission of patients, resulting in more rapid solutions to their health issues. During the group discussions, the managers of both forms of PHCls indicated that medical staff (family doctors, nursing staff) have the same opportunities to express and develop their professional abilities in public and private institutions. 


\section{Conclusions}

1. Managers of public PHCls stated that competition ensures the increase of service quality and the exclusiveness of health care services compared to other forms of service. Managers of private $\mathrm{PHCls}$ also noted the economic competitiveness of services, the necessity of competition in the health care sector, and the degree to which the country's health care policy enables competitive conditions.

2. Managers of public PHCls indicated that a competitive advantage is created through administrative factors, diagnostic capabilities, infrastructure, resources, institutional budget, the number of registered patients, and the location of the institution. Managers of private $\mathrm{PHCls}$ noted that a competitive advantage is created through the improved public image and prestige of the institution, the management of patient queues, improvements to infrastructure, the convenience of the location of the institution, and the quality of the care provided.

3. The majority of managers of both public and private $\mathrm{PHCls}$ indicated that the competitive advantage of a $\mathrm{PHCl}$ depends its form of ownership (public or private).

4. Given that the competitive advantage depends on the form of $\mathrm{PHCl}$ ownership, managers of public $\mathrm{PHCls}$ indicated the following factors for securing a competitive advantage: organisational structure; staff workload; the principle of teamwork; location and facilities; and public image. Managers of private $\mathrm{PHCls}$ indicated the following factors for securing a competitive advantage: a flexible and fast decision-making process; and quicker and easier patient admission, resulting in a more rapid solution to their health issues.

5. The managers of both forms of PHCl indicated that medical staff (family physicians, nursing staff) have the same opportunities to express and develop their professional abilities in public and private institutions.

\section{Limitations And Future Research}

This Lithuanian focus group study has a number of strengths, one of which can be identified in the involvement of managers of both public and private PHCls from every county in the country. One possible limitation surrounds the involvement of managers from PHCls only, and therefore future research might aim towards including respondents from secondary and tertiary institutions. The researchers involved in this study noted that, whilst their work focused on the managers of PHCls, it would be interesting to consider the opinions of patients regarding the potential for value creation within PHCls. The authors point out that this study might itself form a direction for future research, in order to provide comparability between these results and those attained in other countries.

\section{Declarations}

\section{Conflicts of interest}


The authors report no conflicts of interest. The authors alone are responsible for the content and writing of the paper.

\section{Acknowledgements}

The authors would like to thank the participants of group discussions and their views expressed in the qualitative study. The authors would like to thank the Research Council of Lithuania, Klaipeda City Public Health Center, Šiauliai City Health Insurance Fund, Šiauliai City Public Health Center, Panevèžys City Public Health Center, the Municipality of Marijampolè, Public Health Bureau of Utena Region Municipality, the Municipality of Alytus, the Municipality of Telšiai Region, the Municipality of Taurage Region for the conference rooms to conduct the research. The authors would like to thank scientists, anonymous reviewers for their helpful and valuable comments how to improve the paper.

\section{Financial Disclosure}

The authors received no specific funding for this work.

\section{Declaration section}

Consent for publication. Not applicable.

Consent to participate. The informed consent was obtained from all participants. All methods were carried out in accordance with relevant guidelines and regulations.

Availability of data and materials. The datasets used and/or analysed during the current study are available from the corresponding author on reasonable request.

Author contribution. All authors have made contributions to the conception, design, interpretation of data of the work. The authors approved the submitted version of the study.

Ethics approval and consent to participate. The permission (No. BE-2-11) to conduct the research was given by Kaunas Regional Committee of Biomedical Research Ethics (Lithuania). In the permission were discussed ethical aspects about participant's expectations about their role in the research, representation aims and values of the study, participant role and identity. The informed consent to participate in the qualitative research approved by Kaunas Regional Committee of Biomedical Research Ethics (No. BE-211). The authors applied to the Lithuania State Data Protection Inspectorate for study's participant personal data protection (No. DVT2-2009).

\section{References}

1. Bendell, T., Boulter, L., Goodstadt, P. (1998). Benchmarking for competitive advantage. Second edition. Pearson Professional Limited. 
2. Grönroos, Ch. (2011). Value co-creation in service logic: a critical review. Marketing Theory, 11 (3): 279-301. https://doi.org/10.1177\%2F1470593111408177.

3. Herrera, C. A., Rada, G., Kuhn-Barrientos, L., Barrios, X. (2014). Does ownership matter? An overview of systematic reviews of the performance of private for-profit, private not-for-profit and public healthcare providers. PLoS ONE, 9 (12): e93456. https://doi:10.1371/journal.pone. 0093456.

4. Holmqvista, J., Viscontib, L. M., Grönroos, Ch., Guaisd, B., Kessouse, A. (2020). Understanding the value process: value creation in a luxury service context. Journal of Business Research, 120, 114126. https://doi.org/10.1016/j.jbusres.2020.07.002.

5. Oliver, Ch. (1997). Sustainable competitive advantage: combining institutional and resource-based views. Strategic Management Journal, 18 (9): 697-713. https://doi.org/10.1002/(SICl)10970266(199710)18:9<697::AID-SMJ909>3.0.C0;2-C.

6. Porter, M. E. (2010). What is value in health care ? The New England Journal of Medicine, 363: 24772481. https://doi:10.1056/NEJMp1011024.

7. Ravald, A., Grönroos, Ch. (1996). The value concept and relationship marketing. European Journal of Marketing, 30 (2): 19-30. http://dx.doi.org/10.1108/03090569610106626.

8. Rivers, P. A., Glover, S. H. (2008). Health care competition, strategic mission, and patient satisfaction: research model and propositions. Journal of Health Organization and Management, 22 (6): 627-641. http://dx.doi.org/10.1108/14777260810916597.

9. Prajogo, D. I., McDermott, P. (2011). Examining competitive priorities and competitive advantage in service organizations using Importance-Performance Analysis matrix. Managing Service Quality, 21 (5): 465-483. http://dx.doi.org/10.1108/09604521111159780.

10. Wernerfelt, B. (1984). A resource-based view of the firm. Strategic Management Journal, 5 (2): 171180.

\section{Tables}

Table 1. Differences in competitive advantages according to the form of ownership of a $\mathrm{PHCl}$ 


\begin{tabular}{|c|c|}
\hline $\begin{array}{l}\text { Form of } \mathrm{PHCl} \\
\text { ownership }\end{array}$ & Statements of managers regarding competitive advantage \\
\hline \multirow[t]{10}{*}{ Public $\mathrm{PHCl}$} & ...Different organisational structure of the $\mathrm{PHCl} .$. \\
\hline & ...Medical staff are more important than the form of ownership... \\
\hline & ...Unfair competitive conditions... \\
\hline & ...Higher-income patients tend to choose private PHCls... \\
\hline & ... Private PHCls are the first choice of younger patients... \\
\hline & ...Private PHCls possess a more amiable environment for patients... \\
\hline & ...A large institution is more difficult to manage than a small one... \\
\hline & $\begin{array}{l}\text {...Private PHCls can implement innovations more easily, be more creative, and } \\
\text { thus increase patient satisfaction... }\end{array}$ \\
\hline & ...Public PHCls have more bureaucratic obstacles... \\
\hline & ...PHCls offer the services of secondary health care specialists... \\
\hline \multirow[t]{5}{*}{ Private $\mathrm{PHCl}$} & ...Unfair competitive conditions... \\
\hline & ...Cooperation between public and private $\mathrm{PHCls...}$ \\
\hline & ...Communication between family doctor and patient... \\
\hline & ...Good working atmosphere... \\
\hline & ...Patients are offered training on how to manage chronic diseases \\
\hline
\end{tabular}

